\title{
O REI FIEL NA PERSPECTIVA DE ISIDORO DE SEVILHA
}

\section{Andréa Dal Pra de Deus}

RESUMO: O Tardo-Antigo na Hispania visigoda do sétimo século abarca contínuos esforços da teoria política que visam estruturar medidas de apaziguamento de discórdias. A heterogeneidade de interesses da nobreza tencionava a política interna, fragilizando a centralização do poder. Desta problemática, destacamos Isidoro de Sevilha, que através da argumentação acerca da fidelidade do corpo político do reino hispano-visigodo teoriza uma solução para a dificuldade de centralização do poder. A fidelidade é entendida como a observância do bem-comum do Reino, ou seja, a monarquia deve favorecer os interesses coletivos. Cabe ao rei ser correto em sua função, através da prática das virtudes, para que os súditos se espelhem e também pratiquem uma vida política virtuosa. Neste sentido, rei e súditos fiéis é norma para um reino fortalecido e centralizado, segundo a perspectiva isidoriana.

PALAVRAS-CHAVE: Monarquia hispano-visigoda; Teoria política; Isidoro de Sevilha.

ABSTRACT: The Ancient-slow thing in the Hispania visigoda of the seventh century comprises continuous efforts of the political theory that aim to structure measures of peacemaking of discords. The heterogeneity of interests of the nobility was intending the internal politics, fragilizando the centralization of the power. Of this problematics, we detach Isidoro de Sevilha, who through the argumentation about the loyalty of the political body of the Hispanic kingdom - visigodo theorizes a solution for the difficulty of centralization of the power. The loyalty is understood how the observance of the commom good of the Kingdom, in other words, the monarchy must favor the collective interests. It falls to a king to be correct in his function, through the practice of the virtues, so that the subjects are mirrored and so that they practice a political virtuous life. In this sense, king and loyal subjects it is a standard for a strengthened and centralized kingdom, according to the perspective isidoriana.

KEYS-WORDS: Monarchy Hispanic visigoda; Political Theory; Isidoro de Sevilha

No tardo-antigo na Hispania visigoda do sétimo século, notase o emprego de teorias políticas que estruturam uma idéia de centralização à volta do monarca. Este empenho em se argumentar 
em prol da unidade política é resultado de um contexto instável, no qual diferentes grupos de nobres conflitam entre si.

A noção de Rei Fiel exprime uma idéia de "bem-comum" para o reino hispano-visigodo que possibilitaria o comprometimento da nobreza em seguir medidas de centralização do reino. Isidoro de Sevilha em sua obra Sentenças de 615 estrutura o que seria a fidelidade entre as partes políticas do reino, destacando o Rei Fiel. Nas Sentenças, a fidelidade está associada a uma postura diferenciada, a uma vida consagrada. O rei fiel é um exemplo de virtuosidade.

Na própria justificação de Isidoro da função do rei há a idéia, que segue a tradição estóica, de que o rei é dentre os homens de uma comunidade política o mais virtuoso, aquele que consegue dominar seus instintos pessoais de inclinação ao pecado, por isso é natural que se coloque acima dos demais, exercendo sua função de Justiça. A justificação teórica do poder para Isidoro repousa no pecado original. Os governantes políticos são definidos por suas funções repressivas em prol da defesa da família, da propriedade e dos súditos:

Por causa do pecado do primeiro homem, Deus impôs ao gênero humano o castigo da servidão (...) e mesmo que o pecado original seja perdoado pelo batismo dos fiéis, o Deus justo instituiu alguns homens para serem servos e outros para serem senhores a fim de que as más ações dos súditos sejam reprimidas pelo soberano ${ }^{1}$.

O rei, então, por conter as qualidades precisas, tem a função de punir os que não seguem a lei e deste modo não se comprometem com o bem-comum do reino. A legitimidade do rei fiel está diretamente ligada ao respeito à lei, à prática das virtudes.

Notamos, portanto, que o elenco de Isidoro das qualidades necessárias par ao rei no exercício de sua função, qualifica a justiça

\footnotetext{
${ }^{1}$ Isid., Sent., III, 47, 1, p. 492: "propter peccatum primi hominis humano generi poena divinitus illata est servitutis (...) et licet peccatum humanae originis per baptismi gratiam cubctis fidelibus dimissum sit, tamen aequus Deus ideo discrevit hominibus vitam, alios servos constituens, alios dominos, ut licentia male agendi servorum potestate dominantium restringatur".
} 
como a primeira característica. O bom rei está atrelado ao rei justo e mais, ao rei da lei. Para Isidoro de Sevilha, as qualidades do rei devem, em primeiro lugar, responder aos critérios da perfeição evangélica, sendo as ações do rei pautadas no Antigo Testamento. Ancora-se na figura de Davi, o modelo de rei fiel, pois pratica as virtudes. O rei é reconhecido como tal por suas ações corretas, testemunhadas por Deus, dignas de um soberano cristão:

O que governa o mundo bem, temporalmente, reina sem fim na eternidade, e a glória deste século se transforma em glória eterna. Mas os que exercem mal sua realeza por trás de vestes suntuosas e diadema de pedras preciosas caem nus e miseráveis em tormentos do inferno ${ }^{2}$.

O respaldo da teoria de Isidoro de Sevilha a cerca do rei fiel é o reflexo desta idéia na compreensão da nobilitas de que a unidade do reino hispano-visigodo depende das relações entre a monarquia e os súditos. A reciprocidade social seria assegurada pela observância da fidelitas do rei para com seu posto - a monarquia. Por isso, o monarca se qualifica como fiel na medida em que mantém uma conduta correta, virtuosa e atenta às leis.

Sob o rei são colocadas responsabilidades coletivas. Deste modo, a conduta do rei espelha a conduta dos súditos. Nas Sentenças, Isidoro demonstra sua crença de que a maioria dos súditos, quando se submete aos reis injustos, faz transparecer "o mal". Há os que são bons em imitar vícios do rei e relapsos em imitar as virtudes. Os bons súditos, segundo Isidoro, imitam as boas obras dos reis, mas há outros que seguem os maus exemplos:

Como alguns dos súditos bons imitam as obras dos príncipes graças a Deus, assim, facilmente outros muitos seguem seus maus exemplos, mas a maior parte, quando está submetida a príncipes iníquos se mostra má, ao obedecer a seus mandatos, mais por necessidade que por malícia. Outros,

${ }^{2}$ Isid., Sent., III, 48, 6, p. 494: "qui intra saeculum bene temporaliter imperat, sine fine in perpetuum regnat; et de gloria saeculi huius ad aeternam transmeat gloriam. Qui vero prave regnum exercent, post vestem fulgentem et lumina lapillorum, nudi et miseri ad inferna torquendi descendunt". 
por sua vez, são diligentes para seguir os reis no vício, porém indolentes para imitá-los na virtude ${ }^{3}$.

Deste modo, os súditos ao não colocarem em prática uma vida virtuosa à maneira do rei justo, sucumbem em uma vida de vícios e prejudicam a centralização do poder e o conseqüente "bemcomum" almejado por Isidoro. Os súditos que não observam as virtudes facilmente se entregam ao delito de atentar contra a vida do soberano legítimo e tornam-se infiéis ao juramento e inimigos do Reino.

No entanto, é necessário que façamos uma distinção entre os elementos teóricos construídos para reforçar e, inclusive, tentar elevar o poder da realeza acima dos pares nobiliárquicos concorrentes e oponentes diretos do poder do soberano -, com a prática política que contrariava aqueles preceitos teóricos e ideológicos elaborados por elementos integrantes tanto do corpo nobiliárquico como eclesial ${ }^{4}$. $\mathrm{Na}$ prática, a nobreza, mesmo tendo jurado fidelidade ao rei e confirmando seu comprometimento com a centralização do reino, via seus interesses patrimoniais acima dessa elucubração à cerca do rei. Na prática, a nobilitas não assimilava a idéia de "bem-comum", reiteradamente reforçada por Isidoro através da idéia de fidelitas, por exemplo. A manutenção da unidade do Reino hispano-visigodo era de interesse desta nobilitas, uma vez que

${ }^{3}$ Isid., Sent., III, 50, 7, p. 499: "sicut nonnulli bonorum principum Deo placita facta sequuntur, ita facile multi prava eorum exempla sectantur. Plerique autem apud iniquos príncipes necessitate magis quam voto mali existunt, dum imperiis eorum obediunt. Nonnulli autem sicut prompti sunt sequi reges in malum, sic pigri sunt imitari in bonum".

${ }^{4}$ Temos que entender que desde o século IV até o século VIII os preceitos teóricos cristãos sofrem ampla simbiose com elementos teóricos comuns da realidade clássica romana - que denominamos como Romanitas - e também da tradição dos "novos" inquilinos, as monarquias romano-germânicas, que terminaram por construir novas comunidades políticas baseadas no passado imperial romano em sua Pars occidentalis. (FRIGHETTO, R. Algumas considerações sobre as construções teóricas da centralização do poder político na Antiguidade Tardia: cristianismo, tradição e poder imperial. p. 12). 
a administração e política centralizada garantiriam a proteção das fronteiras e afastariam incursões militares, desgastantes economicamente. Entretanto, a unidade não poderia ser mantida mediante a opressão de interesses políticos de cada clã. A idéia de abnegação pessoal, que Isidoro intentava tornar prática, não era uma realidade viável para os nobres. A ambição do poder e a conseqüente concessão de favores para seus clãs de origem produziram inumeráveis "infiéis" ou "bárbaros". Nas fontes de cunho históricocronístico e legislativo ${ }^{5}$ aparece a idéia da barbárie associada à noção de infidelitas, caracterizando aquele que comete algum ato de infidelidade contra o soberano ou contra o reino como bárbaro ${ }^{6}$. Para Isidoro as conspirações contra o príncipe são testes de Deus à clemência do soberano. Na mesma medida em que o rei teme a Deus quando comete um delito, o povo deve temer o soberano, pois tem a certeza de que este fará cumprir as leis e apartar o súdito do mal ${ }^{7}$.

A fonte imediata de soberania após o IV Concílio foi a eleição e o subseqüente juramento do rei e dos súditos, além, é claro, dos atos religiosos que acompanham a ascensão ao trono, como a unção. Portanto, a idéia de que os súditos estavam sujeitos à autoridade do rei foi tomada como parte de uma função cultual. O fiel cristão possui uma obrigação moral e legal com a fé do reino e com a instituição monárquica. Este "culto" é fomentado pela teoria política que se utiliza de subsídios religiosos ou míticos para ilustrar a instituição monárquica à maneira de uma instituição divina.

O rei hispano-visigodo é posto como descendente de Davi e sucessor de Saul e Salomão a fim de validar sua posição como destacada dos demais nobres através de uma escolha divina. A sujeição do corpo político à dinastia de reis escolhidos por Deus é

5 "A posição adotada por João de Bíclaro ao analisar o episódio da rebelião de Hermenegildo contra seu pai Leovigildo entre 579 e 585"; "Essa mesma interpretação está em Isidoro de Sevilha em sua Historia Gothorum e no cânone 75 do IV Concílio de Toledo" (FRIGHETTO, R. Infidelidade e Barbárie na Hispania visigoda. Gerión, Madrid, v. 20, n.1, 2002, p. 502-503).

${ }^{6}$ Ibidem, p. 502.

${ }^{7}$ Isid., Sent., III, 48, 7, p. 494. 
medida natural dentro da justificação teológica que se ampara na Bíblia.

Assim, a obra de Isidoro nos apresenta um modelo de sociedade ideal que propiciaria a unidade necessária para o reino. Nesta sociedade o Rei Fiel é um exemplo de conduta na política. O amparo do rei fiel é a construção moral de seu cargo que concebe o exercício do poder como parte de uma tradição estóica, de prática das virtudes. Isidoro estabelece uma relação de reciprocidade entre a lei e a moral. A submissão do soberano à lei existe em função da característica humana do rei, que submetido a toda sorte de tentações pode vir a sucumbir no vício. Mesmo o soberano sendo posto como uma figura sacralizada, revestido de uma aura espiritual, Isidoro faz questão de alertar que o rei não deixa de ser carne, de estar sujeito aos dissabores do mundo. Por isso, reitera repetidas vezes a prática das virtudes, porque crê que estas afastam do mal quem as pratica. No entanto, ser virtuoso é uma prática, um exercício diário, porque as tentações cercam o rei. Cônscio dessa natureza material do rei, Isidoro lhe sentencia a submissão à lei.

No nosso entender, Isidoro se dedica a instruir a sociedade política hispano-visigoda do sétimo século no que concerne a uma moralidade coletiva. Os instrumentos para a moral estão claramente arraigados na tradição cristã, que valoriza a dedicação pessoal no aprimoramento das virtudes e repulsão aos vícios. Dessa maneira, ao imputar a preceitos cristãos a manutenção do equilíbrio social, emerge a delimitação da fidelitas - um conceito utilizado como recurso da teoria política para o apaziguamento de conflitos pela afirmação de comprometimento entre as parte e também um reforço da nobilitas clerical frente a nobilitas laica. $\mathrm{O}$ rei fiel acopla à sua construção uma série de elementos éticos da política que interagem na construção do reconhecimento da autoridade do soberano. A necessidade política de tornar o reino unificado, em que a autoridade régia aglutine à sua volta interesses de grupos nobiliárquicos que na prática dispunham de fortes apoios regionais impulsiona a construção 
do rei fiel que condensa um sustentáculo social através do posicionamento político em prol da unidade.

\section{BIBLIOGRAFIA}

CAZIER, P. Isidore de Séville et la naissance de L'Espagne catholique. Paris: Beauschesne Éditeur, 1994.

. Les sentences d'Isidore de Seville et le IV Concile de Tolede: réflexions sur les rapports entre L'Eglise et le pouvoir politique en Espagne autour des anées 630. In: Los visigodos, historia y civilización: Antiguedad y cristianismo. Múrcia: 1986.

ISIDORO DE SEVILLA. Etimologías. Madrid: Biblioteca de Autores Cristianos, 1982. 2 v. Edición Bilingüe, texto latino, versión española y notas por José Oroz Reta y Manuel A. Marcos Casquero. Introducción general por M.C. Diaz y Diaz.

. Sentencias. Madrid: Biblioteca de Autores Cristianos, 1971. Edição crítica de Julio Campos e Ismael Roca. (Santos Padres Españoles, II).

FRIGHETTO, R. Algumas considerações sobre o poder político na Antiguidade Clássica e na Antiguidade Tardia. Stylos, Buenos Aires, v. 13, p. 37-47, 2004.

- Infidelidade e Barbárie na Hispania visigoda. Gerión, Madrid, v. 20, n. 1, 2002.

. O rei e a lei na Hispania visigoda: os limites da autoridade régia segundo a Lex Wisigothorum, II, 1-8 de Recesvinto (652-670). In: Seminário Argentina-Brasil-Chile de História Antiga e Medieval, 1, 2007, Curitiba. Instituições, Poderes e Juridições. Curitiba: Juruá, 2007.

- Uma tentativa de unidade político-religiosa na hispania visigoda de finais do século VII: o reinado de Égica. Cultura e Poder na Península Ibérica. Curitiba: Juruá, 2001

GARCÍA Y GARCÍA, A. El Juramento de Fidelidad en los Concilios Visigóticos. In: Innovación y Continuidad en la España Visigótica. 
Toledo: Instituto de Estudios visigóticos-mozárabes de San Eugenio, 1981.

MENENDEZ PIDAL, R. Historia de España. Madrid: Espasa Calpe,1960. v.1.

ORLANDIS, J. Historia del reino visigodo español. Madrid: Rialp, 2006.

2006.

. La vida en España en tiempo de los godos. Madrid: Rialp,

PEREIRA, M. H. da R. Estudos de história da cultura clássica. Lisboa: Fundação Calouste Gulbenkian, 1993.

VIVES, J. Concilios visigóticos e hispanorromanos. Madrid: Instituto Enrique Flórez, 1963. 